\title{
O que fazem acreanos e amapaenses com palavras esdrúxulas?
}

\section{What do Acreanos and Amapaenses do with proparoxytones words?}

\author{
Marilucia Barros de OLIVEIRA * \\ Universidade Federal do Pará (UFPA) \\ Ana Paula Tavares MAGNO** \\ Universidade Federal do Pará (UFPA)
}

RESUMO: trata o presente artigo da variação das proparoxítonas, sob uma perspectiva Geossociolinguística, a partir de dados que integram o banco de dados do projeto Atlas Linguístico do Brasil. O trabalho é um recorte de uma pesquisa mais ampla ainda em andamento sobre o referido fenômeno nas capitais e não capitais da região Norte do Brasil. A amostra utilizada limita-se aos dados recolhidos em dois estados da região, a saber: Acre e Amapá, incluindo-se capitais e não capitais, e é composta por 24 falantes estratificados em sexo (masculino; feminino) e faixa etária (18-30; 50-65). Apenas nas capitais a amostra leva em consideração a escolaridade (ensino fundamental; ensino superior). Ao todo foram avaliados 460 dados. Apresentaremos os resultados referentes a cinco grupos de fatores, sendo dois internos e três externos. Os resultados mostram que a síncope é pouco produtiva nos falares estudados e que os fatores analisados exercem influência sobre seu uso.

PALAVRAS-CHAVE: Proparoxítonas. Geossociolinguística. Atlas Linguístico do Brasil.

ABSTRACT: this article deals with the variation of proparoxytones, from a Geosociolinguistic perspective, based on data that are part of the Brazilian Linguistic Atlas project database. The present article is a clipping of a broader research still underway on the referred phenomenon in the capitals and non-capitals of the northern region of Brazil. The sample used is limited to data collected in two states of the region, namely, Acre and Amapá, including capitals and noncapitals, and is composed of 24 speakers stratified by sex (male; female) and age group (18- 30; 50-65). Only in the capitals the sample takes into account education (elementary school; higher

\footnotetext{
* Doutora em Linguística. Professora da Faculdade de Letras (FALE) e do Programa de Pós-Graduação em Letras (PPGL) da Universidade Federal do Pará (UFPA). E-mail: oliveira.marilucia@ gmail.com.

** Mestranda em Estudos Linguísticos pelo Programa de Pós-Graduação em Letras (PPGL) da Universidade Federal do Pará (UFPA). Bolsista CAPES. E-mail: tavaresmagnoufpa@ gmail.com.
}

Revista Moara, n. 54, ago-dez 2019 ISSN: 0104-0944

Recebido em 19/09/2019

Avaliado em 18/11/2019 
education). In all, 460 data were evaluated. We will present the results for five groups of factors, two internal and three external. The results show that the syncope is not very productive in the speeches studied and that the analyzed factors influence its use.

KEYWORDS: Proparoxytones. Geosociolinguistics. Atlas Linguístico do Brasil.

\section{Introdução}

Neste artigo, abordaremos a variação das proparoxítonas identificada nos dados do Atlas Linguístico do Brasil (ALiB), mais especificamente nos estados do Acre e do Amapá. O estudo segue a orientação da Geossociolinguística - a qual assume a articulação entre a Sociolinguística e a Geografia Linguística para tratamento e análise dos dados - e objetiva descrever, interpretar e mapear o comportamento variável das proparoxítonas, concentrando sua análise na supressão das vogais postônicas não finais.

O trabalho se justifica por contribuir para os estudos acerca do comportamento variável de palavras esdrúxulas no português brasileiro (doravante PB), uma vez que se propõe a analisar a redução das vogais postônicas não finais em tais palavras.

Para contextualizar o tema, apresentaremos resultados de alguns estudos já produzidos a partir da análise da variação de proparoxítonas. Para tanto, realizaremos um breve levantamento bibliográfico acerca de trabalhos geossociolinguísticos produzidos em cada uma das regiões brasileiras, destacando-se as pesquisas desenvolvidas no Norte e Nordeste, a fim de demonstrar um panorama geral da produtividade dessa variação e relacioná-la com seus possíveis condicionadores linguísticos e não linguísticos considerados nas análises.

Será possível visualizar, assim, os direcionamentos tomados por essa variação nos trabalhos realizados com base no $\mathrm{PB}$, bem como será possível estabelecer comparações entre os resultados obtidos nesses referidos estudos, com o intuito de se detectar os fatores mais frequentes e favoráveis quando da aplicação da regra variável em avaliação. Isso permitirá que se indique se o comportamento variável de palavras esdrúxulas no falar de acreanos e amapaenses coincidem com a variação ocorrida em outros falares brasileiros. 
Quadro 01: Breve levantamento bibliográfico acerca do estudo da variação de proparoxítonas por região.

\begin{tabular}{|c|c|c|c|c|}
\hline \multicolumn{2}{|c|}{$\begin{array}{l}\text { ORIGEM DOS } \\
\text { DADOS }\end{array}$} & \multirow{2}{*}{ AUTOR(ES) } & \multirow{2}{*}{$\begin{array}{c}\text { INFORMAÇÕES } \\
\text { METODOLÓGICAS E OUTROS }\end{array}$} & \multirow{2}{*}{ RESULTADOS E CONCLUSÕES } \\
\hline REGIÃO & ESTADO & & & \\
\hline $\begin{array}{l}\text { Região } \\
\text { Norte }\end{array}$ & RO & França (2009) & $\begin{array}{l}\text { Analisa o efeito de seis fatores } \\
\text { linguísticos, a saber: contexto } \\
\text { fonológico precedente, contexto } \\
\text { fonológico seguinte, estrutura silábica } \\
\text { precedente, traço articulatório da } \\
\text { vogal, extensão do vocábulo e tipo de } \\
\text { entrevista. } \\
\text { Analisa o efeito de três fatores } \\
\text { extralinguísticos, a saber: } \\
\text { escolaridade, faixa etária e sexo. }\end{array}$ & $\begin{array}{l}\text { Os resultados apontaram quatro } \\
\text { fatores linguísticos atuantes na } \\
\text { síncope das vogais postônicas não } \\
\text { finais, são eles: tipo de entrevista, } \\
\text { contexto fonológico precedente, traço } \\
\text { articulatório da vogal e contexto } \\
\text { fonológico seguinte. Todos os fatores } \\
\text { extralinguísticos foram relevantes, } \\
\text { dada a seguinte ordem de } \\
\text { importância: faixa etária, escolaridade } \\
\text { e sexo. }\end{array}$ \\
\hline $\begin{array}{l}\text { Região } \\
\text { Nordeste }\end{array}$ & $\mathrm{PE}$ & Silva Filho (2010) & $\begin{array}{l}\text { Controla a influência de três aspectos } \\
\text { linguísticos, são eles: contexto } \\
\text { fonológico precedente, contexto } \\
\text { fonológico seguinte e traço } \\
\text { articulatório da vogal. } \\
\text { Verifica a influência de dois aspectos } \\
\text { sociais, são eles: faixa etária e sexo. }\end{array}$ & $\begin{array}{l}\text { Com base nos aspectos linguísticos, a } \\
\text { quantificação dos dados indicou o } \\
\text { contexto fonológico seguinte e o traço } \\
\text { articulatório da vogal como } \\
\text { facilitadores do processo. Referente } \\
\text { aos aspectos sociais, todos } \\
\text { apresentaram relevância, com } \\
\text { destaque ao fator sexo. }\end{array}$ \\
\hline $\begin{array}{l}\text { Região } \\
\text { Centro- } \\
\text { Oeste }\end{array}$ & MS & $\begin{array}{l}\text { Bueno e Carvalho } \\
\text { (2011) }\end{array}$ & $\begin{array}{l}\text { Observa o comportamento de duas } \\
\text { variáveis linguísticas: contexto } \\
\text { fonológico e classe morfológica. } \\
\text { Observa o comportamento de três } \\
\text { variáveis extralinguísticas: } \\
\text { escolaridade, faixa etária e sexo. }\end{array}$ & $\begin{array}{l}\text { Os dados evidenciaram que todas as } \\
\text { variáveis favoreceram a realização da } \\
\text { síncope, a exceção da variável sexo, } \\
\text { obedecendo a seguinte ordem de } \\
\text { importância: faixa etária, } \\
\text { escolaridade, contexto fonológico e } \\
\text { classe morfológica. }\end{array}$ \\
\hline $\begin{array}{l}\text { Região } \\
\text { Sudeste }\end{array}$ & RJ & Gomes (2011) & $\begin{array}{l}\text { Examina o efeito de nove fatores } \\
\text { internos: ponto de articulação da } \\
\text { vogal tônica, contexto fonológico } \\
\text { precedente, contexto fonológico } \\
\text { seguinte, natureza da sílaba tônica, } \\
\text { traço articulatório da vogal, extensão } \\
\text { do vocábulo e classe gramatical da } \\
\text { palavra. } \\
\text { Examina o efeito de três fatores } \\
\text { externos: sexo, faixa etária e } \\
\text { escolaridade. }\end{array}$ & $\begin{array}{l}\text { A investigação revelou seis fatores } \\
\text { internos que atuaram na síncope da } \\
\text { vogal postônica não final: contexto } \\
\text { fonológico precedente, contexto } \\
\text { fonológico seguinte, traço } \\
\text { articulatório da vogal e classe } \\
\text { gramatical da palavra. Relativo aos } \\
\text { fatores externos, os significativos } \\
\text { foram faixa etária e sexo. }\end{array}$ \\
\hline $\begin{array}{l}\text { Região } \\
\text { Sul }\end{array}$ & PR & Castro (2008) & $\begin{array}{lll}\text { Estuda o } & \text { efeito de três fatores } \\
\text { externos: } & \text { sexo, escolaridade e e } \\
\text { localidade. } & & \end{array}$ & $\begin{array}{l}\text { O estudo indicou que o fator sexo se } \\
\text { mostrou relevante para a redução das } \\
\text { proparoxítonas em paroxítonas; as } \\
\text { informantes do sexo feminino são as } \\
\text { que mais mantêm a forma } \\
\text { proparoxítona dos vocábulos em } \\
\text { estudo. }\end{array}$ \\
\hline
\end{tabular}

Fonte: Produzido pelas autoras. 
Observa-se, a partir do levantamento bibliográfico realizado, coincidências em relação às variáveis avaliadas nos diferentes estudos. Os grupos de fatores linguísticos que atuaram como favorecedores do comportamento variável das proparoxítonas, em ordem de importância, foram: contexto fonológico seguinte, contexto fonológico precedente, traço articulatório da vogal, classe gramatical, tipo de entrevista e estrutura da sílaba tônica. Apesar de não ter sido um fator relevante em tais estudos, resultados de pesquisas realizadas no âmbito de atlas linguísticos regionais apontam a extensão do vocábulo como facilitadora da regra variável. Quanto aos grupos de fatores não linguísticos, todos foram significativos, observando-se a seguinte ordem de relevância: faixa etária, escolaridade, sexo e localidade.

Em trabalho realizado no âmbito do ALiB, Oliveira, Magno e Coimbra (2019) desenvolveram estudo acerca da variação de proparoxítonas nas capitais da Região Norte, à exceção de Palmas (TO), a fim de se observar os grupos de fatores extralinguísticos que favorecem o comportamento variável das vogais postônicas não finais em palavras de acento esdrúxulo. A metodologia utilizada contemplou quarenta e oito informantes, havendo oito por ponto de inquérito, os quais foram distribuídos equitativamente em escolaridade (ensino fundamental; ensino superior), faixa etária (1830; 50-60) e sexo (masculino; feminino). O corpus foi constituído a partir dos dados sonoros do Questionário Fonético-Fonológico e do Questionário Semântico-Lexical do Projeto ALiB, os quais contêm, respectivamente, doze e quinze vocábulos proparoxítonos avaliados.

De modo geral, os resultados indicaram a variação das proparoxítonas como sendo pouco produtiva nos falares estudados, ainda que os grupos de fatores extralinguísticos tenham exercido influência sobre o comportamento variável das proparoxítonas. A manutenção da vogal postônica não final apresentou a mais alta frequência, com 93,6\% dos casos (incluindo-se aí 19,4\% de alteamento), seguida da redução da vogal, a qual correspondeu a 5,4\%. Em relação às variáveis sociais controladas, os resultados apontaram que os mais escolarizados, os jovens e as mulheres inibiram significativamente o uso da síncope. As mulheres mais jovens e com mais escolaridade usaram a forma proparoxítona. Os autores acreditam que as restrições linguísticas, o estigma e a escola funcionaram como um inibidor do fenômeno em estudo nas capitais investigadas. 
Em estudo anterior realizado a partir do Atlas Linguístico Quilombola de Moxotó-Ipanema-PE (ALQUIMIPE), Oliveira e Sá (2018) também observaram a variação de proparoxítonas em cinco comunidades pertencentes a municípios do Sertão de Moxotó e do Vale do Ipanema, ambos situados na Região Nordeste. Em cada localidade investigada foram entrevistados quatro informantes, estratificados igualitariamente em faixa etária (18-40; 50-70) e sexo (masculino; feminino), todos com escolaridade até o ensino fundamental. A esses falantes foram aplicadas as perguntas do Questionário Fonético-Fonológico e do Questionário Semântico-Lexical do ALiB, sendo utilizados, no trabalho em questão, somente seis itens lexicais proparoxítonos, dos quais focalizou-se a redução de apenas dois, quais sejam: fósforo e abóbora.

Os resultados mostraram que a redução foi mais frequente que a forma considerada culta, equivalendo a $60 \%$ do total de realizações. Quanto aos dois itens lexicais analisados, houve uma distribuição bastante diversificada para o item abóbora, o qual apresentou seis variantes de redução silábica, ao passo que fósforo apresentou apenas duas. No tocante aos fatores externos controlados, os autores acreditam que a baixa escolaridade pode ter exercido influência sobre os resultados alcançados, bem como o espaço físico onde a pesquisa foi desenvolvida. Os resultados foram comparados aos do Atlas Linguístico de Pernambuco (ALiPE), o qual apresenta um índice de $40 \%$ de redução das proparoxítonas. Quando se comparam esses dados com os das capitais do Norte, a diferença fica ainda mais evidente, já que nessas a redução é amplamente rejeitada.

Apesar de haver vários estudos sobre o tema, não há pesquisa que se volte para a variação de palavras esdrúxulas nos estados do Acre e do Amapá, a partir dos dados do ALiB, muito menos especificamente sobre a redução de vogais postônicas não finais nos referidos vocábulos. Também não há estudos que se ocupem do mapeamento linguístico a ser produzido com base na regra variável observada. Portanto, ainda que o fenômeno em estudo já tenha sido registrado em diversos espaços geográficos do Brasil, agora a análise é feita sobre dados mais recentes e de modo que permite comparação, já que os procedimentos metodológicos adotados na coleta realizada nos dois estados são semelhantes, conforme veremos a seguir. 


\section{Procedimentos metodológicos adotados}

Nesta seção, apresentaremos os procedimentos metodológicos adotados na investigação, a saber: a escolha da rede de pontos, o perfil dos informantes e a descrição dos questionários, bem como os materiais e métodos utilizados no decorrer do estudo, tais quais os programas computacionais usados durante o desenvolvimento da pesquisa e as diferentes formas de tratamento dos dados.

\subsection{A rede de pontos}

A metodologia utilizada segue as orientações do Projeto ALiB. Para este estudo, o qual consiste em um recorte de uma pesquisa maior ainda em andamento, avaliamos a variação das proparoxítonas em quatro pontos de inquérito que constituem a rede de $\operatorname{pontos}^{1}$ da Região Norte do Brasil, quais sejam:

Quadro 02: Pontos de inquérito investigados.

\begin{tabular}{ccc} 
ESTADO & CAPITAIS & NÃO CAPITAIS \\
\hline Acre & Rio Branco & Cruzeiro do Sul \\
\hline Amapá & Macapá & Oiapoque
\end{tabular}

Fonte: Produzido pelas autoras.

Para cada estado considerado há uma capital e uma não capital. Diferentemente do que tem sido feito tradicionalmente em trabalhos de natureza dialetal, na metodologia do ALiB não se consideram prioritários critérios como antiguidade e grau de isolamento com relação a centros mais desenvolvidos na região.

\section{$1.2 O$ perfil dos informantes}

O perfil dos informantes procura atender a questões espaciais, por isso são filhos das localidade pesquisadas e de pais também da área, mas também inclui o controle de

\footnotetext{
1 A rede de pontos do ALiB-Norte conta com um total de 24 localidades selecionadas de acordo com critérios demográficos, históricos e culturais, tendo-se, também, levado em consideração a extensão de cada Estado e a natureza de seu povoamento na delimitação do número de pontos da área.
} 
variáveis sociais, como escolaridade, faixa etária e sexo. O número total atinge vinte e quatro informantes, distribuídos equitativamente por duas faixas etárias (de 18 a 30 anos e de 50 a 65 anos), contemplando os dois sexos. Apenas nas capitais a amostra leva em consideração a escolaridade: ensino fundamental e ensino superior.

Quadro 03: Estratificação dos informantes por faixa etária, sexo e escolaridade.

\begin{tabular}{cccc} 
INFORMANTE & FAIXA ETÁRIA & SEXO & ESCOLARIDADE \\
\hline 1 & 18 a 30 anos & Masculino & \\
2 & 18 a 30 anos & Feminino & Ensino Fundamental \\
3 & 50 a 65 anos & Masculino & \\
4 & 50 a 65 anos & Feminino & \\
\hline 5 & 18 a 30 anos & Masculino & \\
6 & 18 a 30 anos & Feminino & \\
7 & 50 a 65 anos & Masculino & \\
8 & 50 a 65 anos & Feminino & \\
& Fonte: Produzido pelas autoras. &
\end{tabular}

Nos dados das capitais há oito informantes por ponto, diferentemente dos dados das não capitais, que contemplam apenas quatro (com escolaridade até o $5^{\circ}$ ano do ensino fundamental). Como se vê desse breve perfil, há o interesse de se buscarem as relações língua-fatores sociais como forma de se responder a questões geossociolinguísticas da realidade atual dos falares dos estados do Acre e do Amapá.

\subsection{Os questionários utilizados}

Utilizamos os dados sonoros do Questionário Fonético-Fonológico (QFF) e Questionário Semântico-Lexical (QSL) do ALiB, dos quais consideramos, respectivamente, 12 e 15 questões. 
Quadro 04: Lista de itens lexicais analisados.

\begin{tabular}{|c|c|c|c|}
\hline \multicolumn{2}{|c|}{ QFF } & \multicolumn{2}{|c|}{ QSL } \\
\hline No DA QUESTÃO & ITEM & Nº DA QUESTÃO & ITEM \\
\hline 010 & Lâmpada & 001 & Córrego \\
\hline 011 & Elétrico & 008 & Relâmpago \\
\hline 015 & Fósforo & 019 & Úmida \\
\hline 017 & Pólvora & 026 & Crepúsculo \\
\hline 032 & Abóbora & 080 & Úbere \\
\hline 039 & Árvore & 085 & Libélula \\
\hline 060 & Sábado & 089 & Pálpebras \\
\hline 066 & Número & 103 & Clavícula \\
\hline 118 & Fígado & 113 & Útero \\
\hline 127 & Vômito & 117 & Rótula \\
\hline 133 & Único & 120 & Cócegas \\
\hline 157 & Hóspede & 144 & Bêbado \\
\hline- & - & 194 & Semáforo \\
\hline- & - & 198 & Rótula \\
\hline- & - & $200 / 201$ & Ônibus \\
\hline
\end{tabular}

Fonte: Produzido pelas autoras.

Dos itens que constituem o QFF, analisamos os seguintes contextos: lâmpada, elétrico, fósforo, pólvora, abóbora, árvore, sábado, número, fígado, vômito, único e hóspede. Já do QSL, analisamos os itens córrego, relâmpago, úmida, crepúsculo, úbere, libélula, pálpebras clavícula, útero, rótula, cócegas, bêbado, semáforo, rótula e ônibus.

\subsection{Escuta e transcrição dos dados sonoros}

Inicialmente, recortamos os dados sonoros em faixas de áudio por meio do programa computacional Cool Edit Pro 2.1, o qual é próprio para esse fim. Posteriormente ao recorte dos dados sonoros, iniciamos o processo de transcrição 
fonética dos áudios recortados, a qual foi realizada a partir dos símbolos do Alfabeto Fonético Internacional ${ }^{2}$. Todos os arquivos de áudio em que os informantes enunciaram as respostas esperadas foram transcritos foneticamente, observando-se suas devidas realizações e variações.

\subsection{Processo de codificação dos dados}

Dada a finalização das transcrições fonéticas, codificamos os dados de acordo com as variáveis linguísticas e sociais estabelecidas na metodologia. Cada uma das variáveis avaliadas constituiu um grupo de fatores, em que para cada fator estabelecido foi atribuído um código. No Quadro 05, apresentamos todos os fatores que constituíram seus respectivos grupos.

Quadro 05: Componentes de cada grupo de fatores.

\begin{tabular}{cc} 
GRUPOS & FATORES \\
\hline Qualidade da vogal & $/ \mathrm{a} /, / \mathrm{e} /, / \mathrm{i} /, / \mathrm{o} /, / \mathrm{u} /$ \\
\hline Contexto fonológico anterior & $/ \mathrm{b} /, / \mathrm{s} /, / \mathrm{f} /, / \mathrm{g} /, / \mathrm{i} /, / \mathrm{k} /, / \mathrm{l} /, / \mathrm{m} /, / \mathrm{n} /, / \mathrm{p} /, / \mathrm{h} /, / \mathrm{s} /, / \mathrm{t} /, / \mathrm{v} /$ \\
\hline Escolaridade & Ensino Fundamental e Ensino Superior \\
\hline Município & Rio Branco, Cruzeiro do Sul, Macapá e Oiapoque \\
\hline Estado & Acre e Amapá
\end{tabular}

Fonte: Produzido pelas autoras.

Os códigos atribuídos, dentro das possibilidades, foram escolhidos com base em critérios mnemônicos, não sendo aceita a repetição de um mesmo código dentro de um mesmo grupo.

\subsection{Quantificação, tabulação e mapeamento das variantes identificadas}

Realizados tais procedimentos, o Arquivo de Codificação foi quantificado estatisticamente no programa computacional de regra variável GoldVarbX, o qual

2 O Alfabeto Fonético Internacional, referenciado pela sigla AFI e pela sigla IPA de International Phonetic Alphabet, é um sistema de notação fonética baseado no alfabeto latino, criado pela Associação Fonética Internacional como uma forma de representação padronizada dos sons das línguas naturais faladas no mundo.

Revista Moara, n. 54, ago-dez 2019 ISSN: 0104-0944

Recebido em 19/09/2019

Avaliado em 18/11/2019 
emitiu, considerando cada grupo de fatores estabelecido, a frequência percentual e o peso relativo das variantes identificadas. Após a leitura dos resultados, esses foram organizados em tabelas estruturadas, a partir das quais foi possível elaborar gráficos e outras formas de representação dos resultados obtidos

Por fim, confeccionamos cartas linguísticas produzidas com o auxílio do programa computacional de edição de imagens Photo Scape V3.7, a fim de se demonstrar os limites e alcances da variação das vogais postônicas não-finais nas localidades investigadas.

\section{As localidades pesquisadas}

Nesta seção, apresentaremos algumas informações acerca das localidades pesquisadas, como aspectos históricos, geográficos, populacionais e econômicos, além dos processos de desenvolvimento em vigor nessas áreas. Os pontos de inquérito estão situados nos estados do Acre e Amapá, os quais contaram, ao longo de sua formação, com um amplo povoamento indígena e a forte migração de povos de diferentes regiões.

\subsection{0 estado do Acre}

Rio Branco é a capital do estado do Acre e se estabeleceu como município apenas em 1912, por força de Decreto Federal. Como atesta a história da cidade, além de ser o mais antigo núcleo urbano do estado, Rio Branco constituiu-se como o maior e mais influente município acreano, sendo por isso elevado ao posto de capital.

Figura 01: Localização de Rio Branco e Cruzeiro do Sul no mapa do Acre.

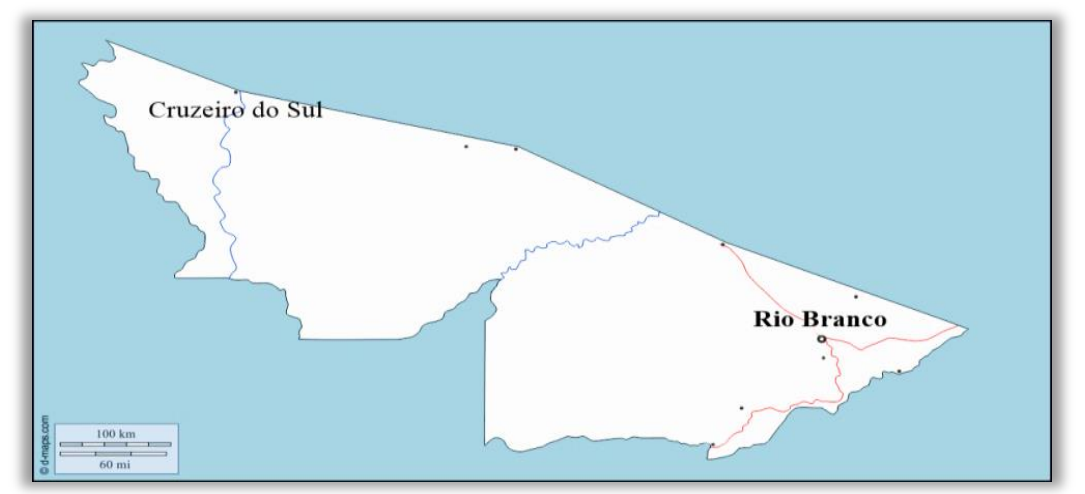

Fonte: D-maps.com, 2019.

Revista Moara, n. 54, ago-dez 2019 ISSN: 0104-0944 
Sua história pode ser dividida em alguns períodos, como a transformação de seringal a cidade (1882-1908), a divisão do espaço urbano (1909-1940), a expansão do município em "colônias-bairro" (1941-1970), a devastação do território em invasões (1970-1998) e o período de obras estruturantes (1999-2005).

A área de sua unidade territorial equivale a $8.834,942 \mathrm{~km}^{2}$, habitada por uma população estimada em 401.155 pessoas. Historicamente, a economia baseia-se no extrativismo vegetal, sobretudo na exploração da borracha, atividade que foi responsável pelo povoamento da região e atraiu a forte migração de nordestinos, os quais se miscigenaram com o povo indígena Kulinaã. O Ciclo do Borracha também despertou o interesse de povos de outras regiões do mundo, como portugueses, libaneses e turcos. Atualmente, a madeira é seu principal produto de exportação e o desenvolvimento da capital segue em expansão.

Cruzeiro do Sul é um município do estado do Acre e fica situado a $632 \mathrm{~km}$ da capital acreana. A região que hoje compreende a cidade era habitada por povos indígenas, mais especificamente os Aruak, Amahuacas, Capanauás, Caxinauás, Jaminauás e Nauás, sendo esses últimos os principais dominantes. Em 1857, com o início das expedições para o alto Juruá, deu-se início ao povoamento do território. Por conta da seca, nordestinos migraram para a região e formaram seringais, o que posteriormente acabou atraindo os primeiros caucheiros peruanos que também adentraram na localidade.

O município é o segundo maior e mais populoso do Acre, com uma área de $8.779,403 \mathrm{~km}^{2}$ e uma população de, aproximadamente, 87.673 habitantes. Atualmente, seu crescimento é tão intenso ao ponto de ser considerada uma das cidades mais desenvolvidas do estado. Igualmente à capital, sua principal atividade econômica é o extrativismo vegetal e exportação de madeira, além do agronegócio e comércio de bens e serviços. Situada às margens do Rio Juruá, a cidade apresenta uma área urbana de $24,794 \mathrm{~km}^{2}$.

\subsection{O estado do Amapá}

Macapá é a capital do estado do Amapá. A história da cidade tem início no período colonial e está relacionada com a defesa e fortificação das fronteiras do Brasil, 
além da preocupação em garantir a ocupação das terras brasileiras. Nesse contexto, a capital se origina de um destacamento militar fixado onde estava situada a antiga Fortaleza de Santo Antônio, por volta de 1740.

Figura 02: Localização de Macapá e Oiapoque no mapa do Amapá.

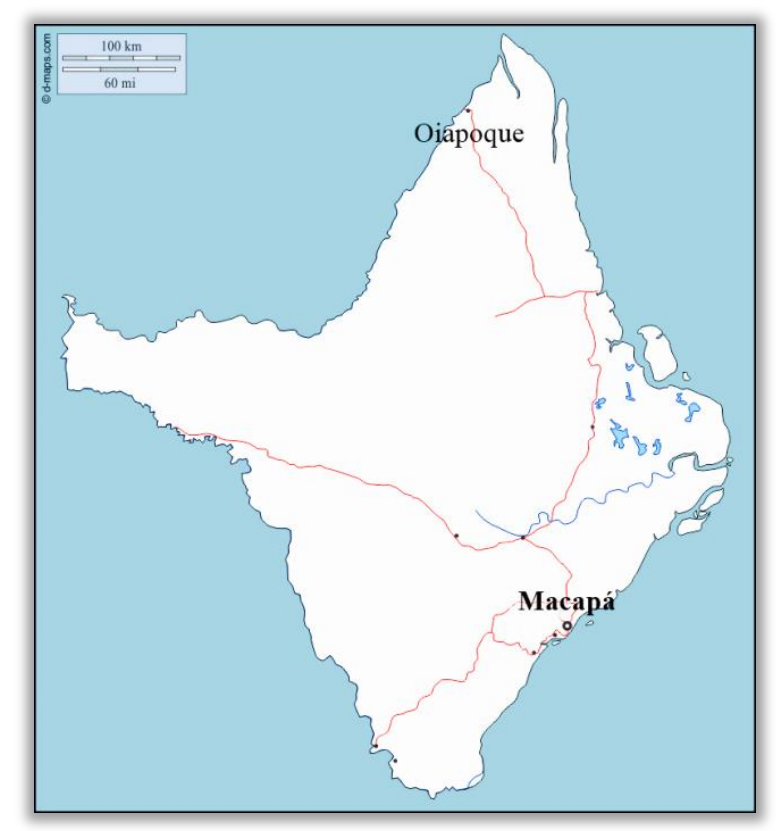

Fonte: D-maps.com, 2019.

Com uma área territorial de $6.563,849 \mathrm{~km}^{2}$, a cidade tem uma população estimada em 493.634 habitantes, fruto de um intenso processo de miscigenação entre povos europeus, africanos e indígenas. Única capital do Brasil cortada pela Linha do Equador, atualmente Amapá vive uma época de crescimento populacional, com sua economia baseada no comércio, indústria, extrativismo e pecuária, atraindo pessoas provenientes de várias regiões brasileiras e promovendo uma transformação no espaço urbano da capital.

Oiapoque é um município do estado do Amapá e fica situado a $550 \mathrm{~km}$ da capital amapaense. O topônimo da localidade é de origem tupi, sendo uma derivação do termo oiap-oca, que significa casa dos Waiãpi, um dos povos indígenas que primeiro habitaram a região, juntamente com os Palikur, Maracá-cunani e Tucuju.

Criado oficialmente em 1945, Oiapoque está situado ao norte do estado e limitase com a Guiana Francesa, sendo a única cidade do Amapá que faz fronteira internacional. Com uma extensão territorial de 23.034,392 km², tem uma população de, 
aproximadamente, 23.627 habitantes. A economia concentra-se na agropecuária, extração de ouro e comércio, o qual tende a crescer com a inauguração da ponte binacional que ligará os dois países, impactando diretamente o fluxo migratório internacional na região.

\section{Apresentação e discussão dos resultados}

Nesta seção, realizaremos a apresentação e discussão dos resultados fornecidos pelo programa computacional de regra variável GoldVarbX, os quais foram descritos e interpretados de acordo com o protocolo geossociolinguístico. Ao todo foram avaliadas cinco variáveis, sendo duas internas e três externas, a saber: qualidade da vogal postônica não-final, contexto fonológico anterior, escolaridade, município e estado.

\subsection{Resultados iniciais e finais fornecidos pelo GoldVarbX}

$\mathrm{Na}$ primeira rodagem gerada pelo programa, a qual contou com 460 dados no total, 408 corresponderam aos casos de manutenção das proparoxítonas e 52 aos casos de redução, correspondendo a $89 \%$ e $11 \%$ de frequência de uso, respectivamente.

$\mathrm{Na}$ segunda rodagem gerada pelo programa, foram retirados alguns fatores de determinados grupos $^{3}$, dada a invariabilidade da regra nesses contextos. Após a exclusão, o número total de dados passou a ser 257, dos quais 205 corresponderam à manutenção e 52 à redução. Em valores percentuais, com base na frequência de uso, a manutenção equivaleu a $80 \%$ e a redução a $20 \%$.

\footnotetext{
3 O programa de regra variável apontou nocautes em alguns fatores dos grupos qualidade da vogal postônica não-final e contexto fonológico anterior, os quais foram excluídos da análise final. Os nocautes decorreram da não aplicação da regra.
} 
Gráfico 01: Frequência das ocorrências de redução e manutenção na segunda rodagem de dados.

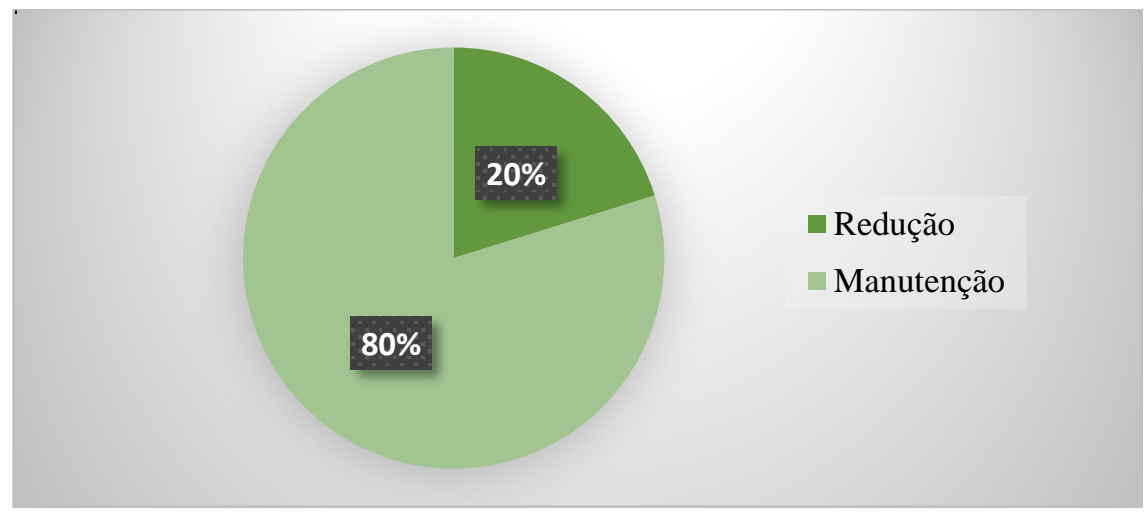

Fonte: Produzido pelas autoras.

É válido ressaltar que, dos informantes entrevistados, 1/3 consistem em falantes com ensino superior, o que pode ter inibido o processo de redução, uma vez que a escola funciona como controladora dessa regra variável.

\subsection{A variável qualidade da vogal postônica não final}

Na presente análise, avaliamos dois grupos de fatores linguísticos. O grupo de fatores qualidade da vogal postônica não-final foi o primeiro grupo a ser selecionado pelo programa de regra variável. Os resultados referentes aos fatores desse grupo estão dispostos na Tabela 01 .

Tabela 01: Qualidade da vogal postônica não final.

\begin{tabular}{ccccccc}
$\begin{array}{c}\text { QUALIDADE } \\
\text { DA VOGAL }\end{array}$ & APLICAÇÃO/TOTAL & $\%$ & P.R. & \multicolumn{2}{c}{ EXEMPLOS } \\
\hline /e/ & $26 / 78$ & 33.3 & 0.942 & Úbere & $\rightarrow$ & {$[$ ['ubri] } \\
\hline /o/ & $24 / 99$ & 24.2 & 0.305 & Fósforo & $\rightarrow$ & {$[$ ['fosfro] } \\
\hline /a/ & $2 / 80$ & 2.5 & 0.155 & Bêbạdo & $\rightarrow$ & {$[$ ['bebo $]$}
\end{tabular}

Fonte: Produzido pelas autoras.

Os resultados mostram que a redução de palavras esdrúxulas foi mais frequente em contexto de vogal média anterior /e/, o qual favorece significativamente a aplicação da regra, com peso relativo igual a 0.942 , o maior obtido na análise quantitativa. A vogal média posterior /o/, por sua vez, apresentou frequência de uso correspondente a 
$24.2 \%$ do total de ocorrências, e peso relativo equivalente a 0.305 , o que indica que a probabilidade de aplicação da regra é desfavorecida diante dessa vogal. O mesmo ocorre com a síncope da vogal baixa /a/, uma vez que essa apresentou baixa frequência, $2.5 \%$, e baixo peso relativo, 0.155 , indicando uma probabilidade de aplicação ainda mais inferior do que a verificada para $/ \mathrm{o} /$.

\subsection{A variável contexto fonológico anterior}

O contexto fonológico anterior foi o segundo grupo de fatores linguístico avaliado e o terceiro a ser selecionado pelo programa. Os resultados obtidos evidenciam uma interação entre esse grupo e o grupo de fatores qualidade da vogal postônica nãofinal. Os resultados referentes aos fatores desse grupo estão dispostos na Tabela 02.

Tabela 02: Contexto fonológico anterior.

\begin{tabular}{|c|c|c|c|c|c|}
\hline $\begin{array}{l}\text { CONTEXTO } \\
\text { ANTERIOR }\end{array}$ & APLICAÇÃO/TOTAL & $\%$ & P.R. & \multicolumn{2}{|c|}{ EXEMPLOS } \\
\hline /f/ & $12 / 30$ & 40 & 0.942 & Fóśforo & $\rightarrow \quad$ ['fosfro $]$ \\
\hline$/ \mathrm{v} /$ & $10 / 47$ & 21.3 & 0.824 & Pólvora & $\rightarrow \quad[$ 'powvre $]$ \\
\hline$/ \mathrm{b} /$ & $13 / 68$ & 19.1 & 0.676 & Abóbora & $\rightarrow \quad\left[a^{\prime}\right.$ bobre $]$ \\
\hline$/ \mathrm{p} /$ & $5 / 70$ & 7.1 & 0.135 & Hóspede & ['ospi $]$ \\
\hline$/ \mathrm{h} /$ & $1 / 7$ & 14.3 & 0.083 & Córrego & $\rightarrow \quad$ ['kohgv $]$ \\
\hline$/ \mathrm{s} /$ & $10 / 23$ & 43.5 & 0.301 & Cócega & $\rightarrow \quad[$ 'koske $]$ \\
\hline$/ \mathrm{t} /$ & $1 / 12$ & 8.3 & 0.034 & Rótula, & $\rightarrow \quad[$ 'hote $]$ \\
\hline
\end{tabular}

Fonte: Produzido pelas autoras.

Os resultados estatísticos revelam que, em termos de frequência de uso, a redução de proparoxítonas foi mais recorrente em casos onde a vogal postônica nãofinal estava precedida das consoantes /s/, /f/, /v/, /b/, /h/, /t/ e /p/, em ordem decrescente, em que a redução atuou de forma mais recorrente no grupo das fricativas, em detrimento do grupo das oclusivas. Quanto ao peso relativo, a consoante fricativa labiodental surda /f/ recebeu o maior valor, 0.942, seguida da consoante fricativa labiodental sonora /v/, com 0.824, o que poderia levar a pensar que há alta 
probabilidade da regra se aplicar quando a vogal variável estiver diante desses contextos fonéticos. Mas isso precisa ser reavaliado levando-se em consideração a atuação concomitante de outro fator, o que faremos após a exposição dos resultados dos demais contextos.

A consoante oclusiva bilabial sonora /b/ também favorece a redução, dado seu peso relativo igual a 0.676 . A oclusiva bilabial /p/ desfavoreceu a regra, com peso igual a 0.135 . As consoantes fricativas $/ \mathrm{s} / \mathrm{e} / \mathrm{h} /$, e a oclusiva /t/, também apresentaram peso inibidor, com $0.301,0.083$ e 0.034 , respectivamente.

Aparentemente as fricativas parecem exercer efeito positivo sobre a regra, mas é preciso avaliar um fator extremamente importante no estudo do fenômeno em avaliação, a estrutura silábica. É preciso notar que os contextos que mais favoreceram a regra são compostos de estruturas em que, apagada a vogal postônica não final, tem-se um contexto ótimo para a formação de grupos consonantais, como em fósforo, abóbora, árvore. No caso de rótula, embora se tenha uma possibilidade de formação do referido grupo, ele não é produtivo na língua portuguesa; ocorrendo normalmente na fala infantil.

Esses resultados nos ajudam também a compreender os índices obtidos para a qualidade da vogal pós-tônica não final, pois notamos que os contextos de vogais avaliados que receberam alto peso relativo apresentam alta probabilidade de restruturação silábica. Essa possibilidade deve contribuir significativamente para desconstrução da estrutura proparoxítona.

\subsection{A variável escolaridade}

A variável escolaridade foi o segundo grupo de fatores selecionado pelo programa e seus resultados apontam a redução de proparoxítonas como uma variante estigmatizada. Na Tabela 03, estão dispostos as frequências e os pesos relativos que confirmam essa avaliação. 
Tabela 03: Escolaridade.

\begin{tabular}{cccc} 
VOGAL & APLICAÇÃO/TOTAL & $\%$ & P.R. \\
\hline Ensino Fundamental & $23 / 87$ & 26.4 & 0.661 \\
\hline Ensino Superior & $6 / 92$ & 6.5 & 0.204
\end{tabular}

Fonte: Produzido pelas autoras.

Os menos escolarizados foram os que mais utilizaram a forma reduzida das palavras esdrúxulas. $\mathrm{O}$ peso relativo acompanhou os resultados percentuais, visto que os falantes com escolaridade até o ensino fundamental também receberam o maior peso relativo, o qual equivaleu a 0.661 , favorecendo a aplicação da regra. Em contrapartida, os falantes com ensino superior apresentaram peso relativo igual a 0.204 , inibindo o uso da variante reduzida e, consequentemente, o processo variável. Esses resultados foram ao encontro dos resultados obtidos no estudo de Oliveira, Magno e Coimbra (2019), o qual mostra que a redução entre os informantes com ensino superior também é baixa, com 2,5\%. Com relação ao ensino fundamental, os resultados apontam semelhanças com os resultados obtidos no estudo de Oliveira e Sá (2018), em que os autores acreditam que a baixa escolaridade tenha influenciado nos altos índices de redução das proparoxítonas.

\subsection{A variável município}

Dos cinco grupos de fatores analisados, dois foram eliminados pelo programa, dentre os quais está a variável município. Embora não tenha sido selecionado, os resultados correspondentes a esse grupo serão apresentados neste estudo. Na Figura 01, tem-se a distribuição da redução e manutenção nos municípios investigados. 
Figura 01: A incidência de redução e manutenção das proparoxítonas nos municípios analisados.

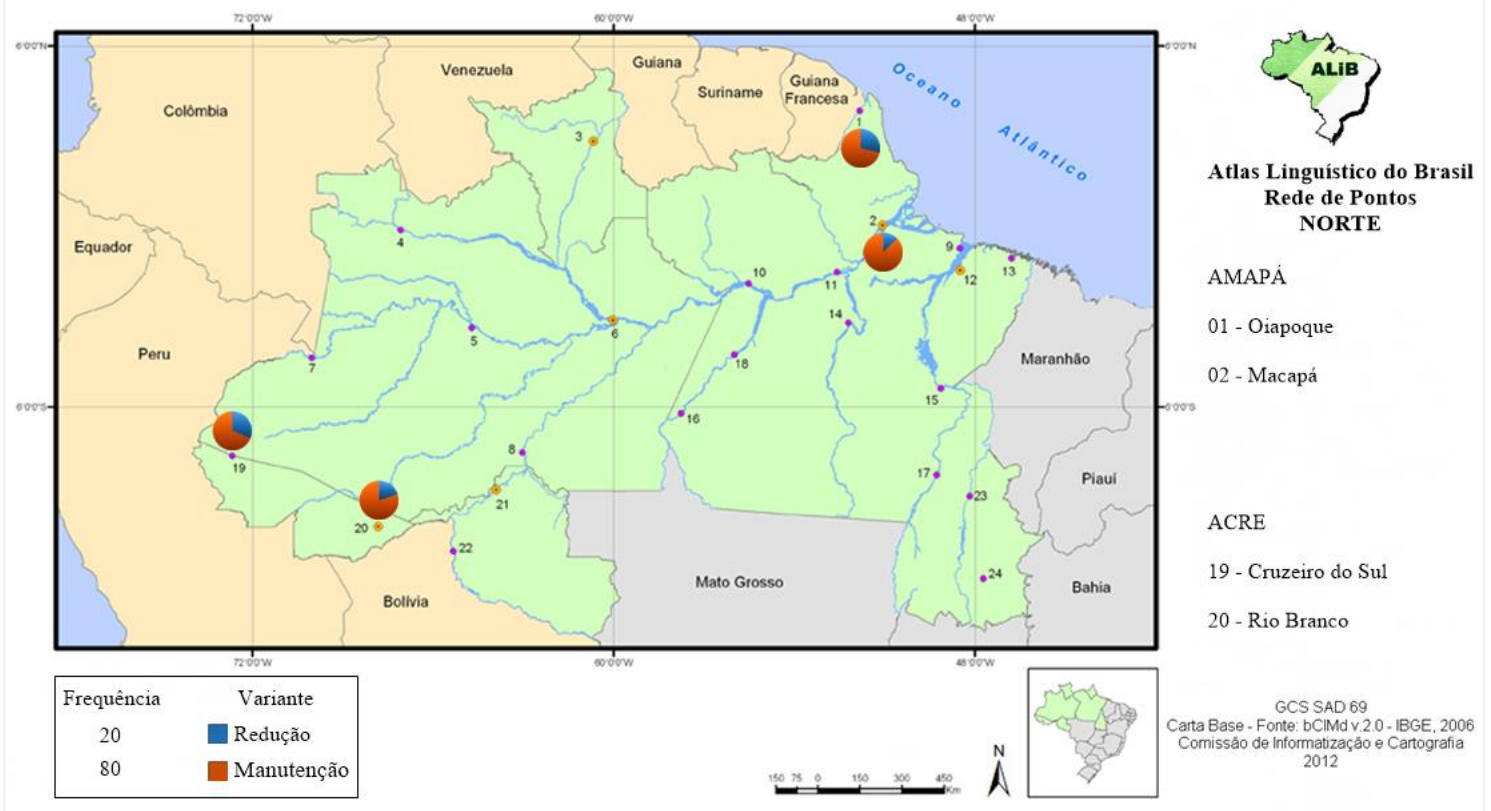

Fonte: Carta Base do Atlas Linguístico do Brasil - Eixo Regional Norte, 2012. Adaptado pelas autoras.

A distribuição mostra, claramente, que nos municípios analisados, a redução não apresenta uma frequência de uso expressiva, ainda que haja diferenças a serem observadas no comportamento variável presente nas capitais e nas não-capitais.

No estado do Acre, os resultados revelam que Cruzeiro do Sul foi a localidade que mais favoreceu a aplicação da regra, a qual obteve peso relativo que oscilou entre 0.654 e 0.707 , bem acima da capital Rio Branco, a qual apresentou peso entre 0.475 e 0.484 , desfavorecendo o processo variável nessa localidade.

No estado do Amapá, o município Oiapoque apresentou peso relativo oscilante entre 0.537 e 0.630 , favorecendo a aplicação da regra de redução, ao passo que a capital Macapá obteve peso que ficou entre 0.372 e 0.397 , desfavorecendo a aplicação da regra e sendo a localidade com o menor peso relativo registrado.

Esses resultados mostram que a resistência ao fenômeno está no âmbito das capitais, visto que tanto Rio Branco quanto Macapá foram desfavoráveis à aplicação da regra, diferentemente das não capitais Cruzeiro do Sul e Oiapoque, as quais favoreceram o fenômeno de redução das palavras esdrúxulas. 


\subsection{A variável estado}

O grupo de fatores estado foi o segundo a ser eliminado pelo programa. Igualmente ao feito com o grupo de fatores município, seus resultados serão apresentados a partir da Figura 02.

Figura 02: A incidência de redução e manutenção das proparoxítonas nos estados analisados.

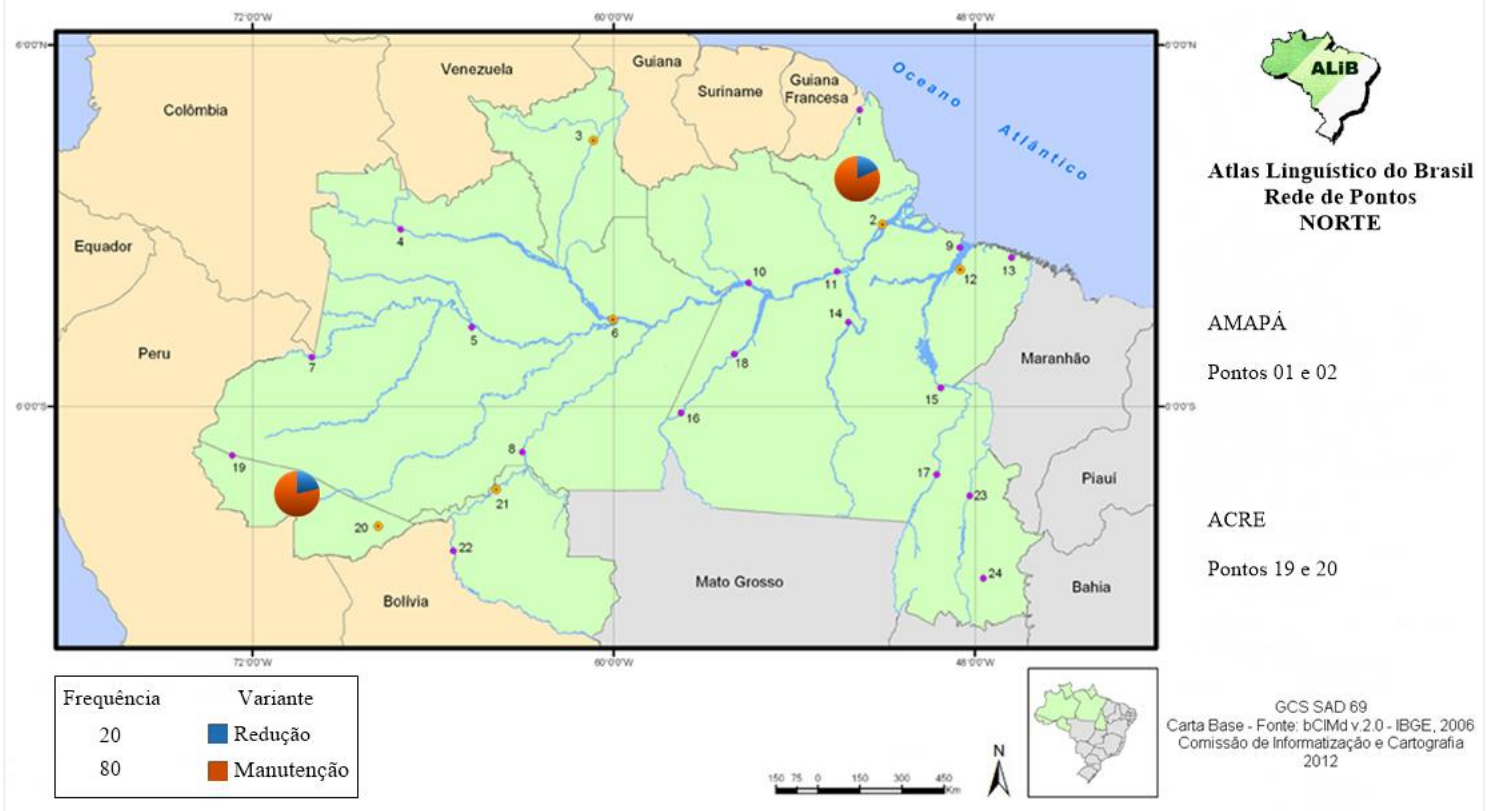

Fonte: Carta Base do Atlas Linguístico do Brasil - Eixo Regional Norte, 2012. Adaptado pelas autoras.

O estado do Acre apresentou a maior frequência de uso das formas reduzidas, em detrimento do estado do Amapá. Somente o Acre favoreceu a aplicação da regra, com peso relativo que oscilou entre 0.507 e 0.550, ao passo que o Amapá obteve peso variável entre 0.447 e 0.493 , desfavorecendo o fenômeno. É válido ressaltar que, embora o estado do Amapá não favoreça a aplicação da regra, esse desfavorecimento é bastante tímido, visto que o peso relativo atribuído a ele é muito próximo do ponto neutro 0.500. Acredita-se que a ampla migração nordestina para o estado do Acre tenha contribuído para esse resultado, uma vez que, como mostrou o estudo de Oliveira e Sá (2018), a redução de palavras esdrúxulas é bastante expressiva nessa região, principalmente em comunidades quilombolas. 


\section{Considerações finais}

Os resultados apresentados neste trabalho mostram que a redução de palavras esdrúxulas não é muito produtiva nas localidades analisadas. Esse recorte da pesquisa mais ampla confirma os resultados obtidos a partir dos dados de outros municípios e estados, os quais também apontam as formas reduzidas como pouco recorrentes na Região Norte, com base nos dados do ALiB.

Os resultados referentes aos fatores linguísticos revelam que a possibilidade de reestruturação silábica é um mecanismo que contribui para a desconstrução da estrutura proparoxítona. Quanto aos fatores externos, os resultados apontam a relação do fenômeno com a baixa escolaridade e o Acre como o estado em que o fenômeno mais se difundiu. A forte migração nordestina deve ter efeito sobre essa produtividade.

Por fim, resta dizer que, no estado do Acre e do Amapá, a regra é inibida e apresenta baixa frequência. Também é possível apontar diferença de uso nas capitais e não capitais estudadas.

\section{REFERÊNCIAS}

BUENO E. S. S; CARVALHO, M. P. Aspectos sociolinguísticos da síncope nas proparoxítonas no português falado em Dourados-MS. Websociodialeto (Online), v. 3, p. 65-86, 2011. Disponível em: <http://www.sociodialeto.com.br/edicoes/8/09052011091636.pdf>. Acesso em: 20 ago. 2019.

CASTRO, V. S. A redução de proparoxítonas no português do Brasil: estudo com base em dados do Atlas Linguístico do Paraná (ALPR). Estudos Linguísticos, São Paulo, v. 37, n.2, p. 113-121, 2008.

FRANÇA, S. A. O apagamento da vogal postônica não-final por falantes de Jaru Estado de Rondônia. Acta Scientiarum. Language and Culture: Maringá, v.31, n. 2, p.169-182, 2009.

GOMES, D. K. Síncope das vogais postônicas não-finais: variação na fala popular urbana do Rio de Janeiro. Rio de Janeiro: Diadorim, v. 8, p. 81-102, 2011.

OLIVEIRA, M. MAGNO, A. P. COIMBRA, D. Apagamento de vogais postônicas nãofinais nas capitais do Norte do Brasil. In: BENÇAL, D. R. COSTA, D.S.S. (Org.). Estudos linguísticos em foco: perspectivas sincrônica e diacrônica. Londrina: Eduel, 2019, p. 414-426. 
OLIVEIRA, M. SÁ, E. Redução das proparoxítonas no Atlas Linguístico Quilombola de Moxotó-Ipanema de Pernambuco. In: SÁ, E. OLIVEIRA, M. SANCHES, R. (Org.). Diversidade linguística em comunidades tradicionais. São Paulo: Pontes Editores, 2018, p. 17-36.

SILVA FILHO, E. B. Uma descrição das proparoxítonas na variedade não padrão de Jabotão - PE. Dissertação (Mestrado em Letras) - Universidade Federal de Pernambuco, $\quad 2010.2$ Decife, Disponível <http://www.pgletras.com.br/2010/dissertacoes/diss-Eraldo-Batista.pdf>. Acesso em: 20 ago. 2019. 